\title{
HURRICANE CAUSES RESOURCE AND POLLINATION LIMITATION OF FRUIT SET IN A BIRD-POLLINATED SHRUB
}

\author{
BEVERLY J. RATHCKE ${ }^{1}$ \\ Department of Biology, University of Michigan, Ann Arbor, Michigan 48109-1048 USA
}

\begin{abstract}
Hurricanes can strip leaves from plants and provide other stresses that can reduce resource availability for subsequent reproduction. In addition, hurricanes commonly reduce populations of bird pollinators. I measured both resource and pollination limitation of fruit set for Bahama Swamp-bush (Pavonia bahamensis) on San Salvador Island in the Bahamas before and after two seasons of hurricanes.

Before the hurricanes in the winter flowering season in 1994-1995, fruit set of $P$. bahamensis was $100 \%$ for most shrubs. After a mild hurricane, in 1995-1996, fruit set was 48\%. After the severe Hurricane Lili (Category 2) in 1996-1997, mean fruit set was only $11 \%$. In both years after the hurricanes, lower fruit set reflected resource limitation. In 1996-1997 after Hurricane Lili, fruit set was severely reduced an additional $74 \%$ by pollination limitation.

Pollination limitation was caused by declines of the two bird pollinators, Bananaquits and Bahama Woodstars. In 1994-1995, both species were frequent visitors to flowers, but in 1996-1997 these birds were rarely seen on the island. A concurrent mist-netting study indicated that Bananaquit populations were decimated after Hurricane Lili in 1996. Nectar removal was virtually absent, and pollen deposition on stigmas was low. In 1994-1995, $98 \%$ of the stigmas had received pollen by the end of floral life. In contrast, in 1996-1997, $51 \%$ of the flowers had received no pollen, supporting the conclusion that pollination limitation of fruit set was strong. There was no compensatory pollination by other pollinators, either other bird species or insects.

These results indicate that severe hurricanes can affect fruit set directly through resource limitation and indirectly through reducing bird pollinators and causing pollination limitation of fruit set. Reduced fruit set after a hurricane could be especially disadvantageous because hurricanes can create sites for plant recruitment. Although resource limitation of fruit set may affect many plant species, bird-pollinated species may be faced with a double jeopardy of resource limitation of fruit set and pollination limitation of fruit set. Whether this disadvantage affects the recruitment of bird-pollinated plants after hurricanes or their adaptations for recruiting after hurricanes remains to be examined.
\end{abstract}

Key words: Bahamas; Bahama Swamp-bush; Bananaquit pollination; fruit set; hurricane effects; island plant pollination; nectarivorous birds; Pavonia bahamensis; pollination limitation.

\section{INTRODUCTION}

Many recent studies have documented that hurricanes can strip plants of their leaves and provide other stresses, such as high rainfall, high winds, or salt spray, which destroy flower and fruit resources for some time afterwards (e.g., Vandermeer et al. 1990, Reilly 1991, Roth 1992, Walker et al. 1992, Boose et al. 1994, Zimmerman et al. 1994, Bronstein and Hossert-McKey 1995, Grant et al. 1997, Pascarella 1998). These stresses could act directly to decrease the ability of plants to produce flowers or fruit after the hurricane. Hurricanes also commonly devastate populations of nectarivorous birds, probably because these birds are left with few nectar or fruit resources (Askins and Ewert 1991, Lynch 1991, Waide 1991, Will 1991, Wauer and Wunderle 1992, Wunderle et al. 1992, Wunderle 1995, Mur-

Manuscript received 4 January 1999; revised 17 May 1999; accepted 17 May 1999; final version received 7 June 1999.

${ }^{1}$ Email: brathcke@umich.edu. phy et al. 1998). This decline in bird pollinators seems likely to affect subsequent pollination of bird-pollinated plants. However, little is known about how hurricanes affect subsequent fruit set either directly through resource limitation of fruit set or indirectly through pollination limitation of fruit set. Here I evaluate both resource limitation and pollination limitation of fruit set after hurricanes on San Salvador Island, Bahamas, for a bird-pollinated shrub, Bahama Swampbush, Pavonia bahamensis Hitchc. (Malvaceae).

Bahama Swamp-bush is endemic to the Bahamas and is also limited to narrow zones of habitat near mangroves along the ocean or hypersaline lakes (Correll and Correll 1982, Smith 1993, Rathcke et al. 1996). Shrubs show seasonal steady-state flowering (sensu Gentry 1974) so few flowers are available at any one time. As a consequence, both shrub and flower populations are small. The limited distribution and small populations of this species may make it especially vulnerable to environmental changes and habitat destruction (Rathcke 1998). 
TAble 1. Pollination syndrome of Bahama Swamp-bush, Pavonia bahamensis (Malvaceae), compared to the typical birdpollination syndrome (modified from Rathcke, unpublished manuscript).

\begin{tabular}{lll}
\hline \hline \multicolumn{1}{c}{ Trait } & \multicolumn{1}{c}{ Typical } & \multicolumn{1}{c}{ Pavonia Bahamensis } \\
\hline Corolla color & vivid; red & green; yellow anthers \\
Odor & none & none \\
Shape & tubular corolla & calyx and petals form tube \\
Nectar & ample & ample \\
Volume $(\mu \mathrm{L})$ & $\sim \ldots$ & $(>100 \mu \mathrm{L} /$ flower/day $)$ \\
Concentration & $\sim 20 \%$ sucrose & $20 \%$ sucrose-equivalents \\
Secretion & continuous & continuous \\
Flower opening & day & day \\
Phenology & steady-state & seasonal steady-state \\
\hline
\end{tabular}

To estimate resource and pollination limitation on fruit set, I compare the fruit set (fruit/flower) of $P$. bahamensis under different pollination treatments before and after hurricanes, and I propose new relative measures of resource and pollination limitation for comparisons. Resource limitation of fruit set was estimated as percentage of fruit set of flowers with augmented pollen relative to the maximum fruit set of flowers observed before the hurricanes. Pollination limitation was estimated as percentage of fruit set of naturally pollinated flowers relative to the fruit set of flowers with augmented pollen. I also measured pollen deposition and nectar removal as indicators of flower visitation and pollination, and I relate these indicators to observations of flower visitation by birds and to percent fruit set over three flowering seasons.

\section{Study Species}

\section{Pavonia bahamensis}

Pavonia bahamensis Hitchc. (Malvaceae) is a shrub or small tree that is endemic to islands in the southeastern Bahamas Archipelago (i.e., San Salvador, Crooked Island, Acklins Island, Turks and Caicos; Correll and Correll 1982). San Salvador is the northernmost island where it is found. Pavonia bahamensis grows in rocky coastal thickets (Correll and Correll 1982, Smith 1993, Fryxell 1999) and along the shores of hypersaline lakes just inland and adjacent to mangroves (Rathcke et al. 1996).

The major period of flowering for P. bahamensis on San Salvador is November through January (B. Rathcke, personal observations, and unpublished data from herbarium collections). A few flowers can be found at other times of the year. For the Bahamas Archipelago, Correll and Correll (1982) report flowering throughout the year. Flowers open continuously throughout the day, and plants typically have few open flowers per day (seasonal steady-state flowering, Gentry 1974) over the winter-flowering months (see also Rathcke et al. 1996, Rathcke 1998; Rathcke, in press).

Flowers have many characteristics typical of birdpollinated species (Howe and Westley 1988), except the corolla is green, not red or vivid (Table 1; see also Rathcke et al. 1996, Rathcke 1998; Rathcke, in press). Flowers have no detectable odor, the calyx forms a tube that contains large amounts of nectar that is relatively dilute. Flowers open continuously throughout the day and secrete nectar continuously.

Pavonia bahamensis depends upon bird visitors for fruit set. Flowers do not self-pollinate and plants are weakly self-compatible if at all (Rathcke 1998; Rathcke, in press).

Flowers are unlikely to self-pollinate because the anthers are separated in distance from the stigma (herkogamy) and are partly protogynous; i.e., the stigma becomes receptive before the anthers release pollen but remains receptive as pollen is later released (Rathcke, in press).

\section{Bird pollinators}

Two bird species, Bananaquits (Coereba flaveola: Emberizidae, Coerebinae), also called the Bahama Honeycreeper, and Bahama Woodstars (Calliphlox evelynae: Trochilidae), were the only major flower pollinators observed visiting flowers of $P$. bahamensis over three major flowering periods in December and January, 1994-1995, 1995-1996, and 1996-1997 (Rathcke et al. 1996, Rathcke 1998). These two species are the only nectarivorous birds on the island (Murphy et al. 1998). Although other birds, especially warblers, may occasionally visit flowers for nectar, I never saw them visit $P$. bahamensis. I observed a single foraging bout by a Bahama Mockingbird (Mimus gundlachii: Mimidae) in January 1997.

Bananaquits are very common on San Salvador (White 1991). In a mist-net study of birds over three years (January 1994, 1996, and 1997) on San Salvador within $100 \mathrm{~m}$ of my study site, Bananaquits made up $56 \%$ of resident captures in three habitats; thicket, mangrove, and disturbed (Murphy et al. 1998). Bahama Woodstars were not captured successfully by mist nets and their abundance cannot be quantified, but they were observed in the area (Murphy et al. 1998).

\section{Research Site}

San Salvador is one of the easternmost islands in the Bahama Archipelago $\left(24^{\circ} 05^{\prime} \mathrm{N}, 74^{\circ} 30^{\prime} \mathrm{W}\right.$; Shaklee 1996). The island is about $600 \mathrm{~km}$ east south east of Miami, Florida, and $340 \mathrm{~km}$ north of Cuba. San Salvador Island is approximately $19 \mathrm{~km}$ long and $8 \mathrm{~km}$ 
wide (Smith 1993). The study site is located near the Bahamian Field Station at the northeastern end of the island near Graham's Harbor. I studied shrubs growing along the southern edge of Reckley Hill Pond, a small hypersaline pond southeast of the Bahamian Field Station.

Annual temperature variation on San Salvador is only $6^{\circ} \mathrm{C}$ with the coolest months averaging $22^{\circ} \mathrm{C}$ (January and February) and the warmest months averaging $28^{\circ} \mathrm{C}$ (July and August; Shaklee 1996). Total annual mean rainfall on San Salvador is $1007 \mathrm{~mm}$ (Shaklee 1996). The rainiest month is October with $205 \mathrm{~mm}$ recorded, and this is within the major hurricane season (August to November) which often brings heavy rains (Shaklee 1996).

The original vegetation of San Salvador was probably dominated by marine tropical woodland with mahogany, Swietenia mahogoni, but these forests were cut with the establishment of plantations in the 1700s and 1800s (Eshbaugh and Wilson 1996). The current vegetation reflects this human disturbance (Eshbaugh and Wilson 1996), and the general vegetation is classified as a "scrubland" community (Smith 1993).

Hurricanes are more common in the Bahamas Archipelago, including San Salvador and perhaps the Lesser Antilles, than most other areas bordering the Caribbean Basin or the Gulf of Mexico (Shaklee 1996). Between 1899 and 1994, 13 hurricanes have passed directly over San Salvador (0.12/yr), but 33 hurricanes have affected San Salvador (0.34/yr, or about once every 3 yr; means calculated from Shaklee 1996). However, there were no hurricanes between 1966 and 1978, and none again between 1981 and 1994 (Shaklee 1996) when the initial pollination study on $P$. bahamensis was done in winter 1994-1995. Therefore, the plants studied here had experienced a relatively long period (14 yr) with no hurricanes before 1995-1996.

On 30 July 1995, Hurricane Erin, a Category 1 hurricane, passed west of San Salvador Island with winds up to 75 miles per hour and heavy rains on San Salvador (Bahamas Department of Meteorology, no date). Human damage was fairly minimal, and there was little obvious damage to plants.

In 1996, three hurricanes occurred on or near San Salvador. The most severe hurricane was on 19 October when the eye of Hurricane Lili passed directly over San Salvador Island with winds up to $169 \mathrm{~km} / \mathrm{h}$ and with heavy rainfall $(7.11 \mathrm{~cm}$ on San Salvador over four days starting 17 October; Bahamas Department of Meteorology, no date). Lili was a Category 2 storm, and it caused extensive damage to buildings. It stripped many trees of their leaves (Murphy et al. 1998). In addition, Hurricane Bertha passed to the east of San Salvador on 10 July 1996 with high winds, and Hurricane Fran passed far to the east on San Salvador on 3 September 1996 with little apparent effect.

\section{Methods}

I studied the pollination biology of $P$. bahamensis for three winter flowering seasons during the following dates: 23 December 1994 to 2 January 1995; 17 December 1995 to 4 January 1996; and 17 December 1996 to 5 January 1997. This period encompasses the major flowering period for $P$. bahamensis on San Salvador. Most available flowering plants are permanently tagged and followed.

Percent fruit set (FS) is calculated as $\% \mathrm{FS}=100 \times$ (fruit/flower). For flowers that do not set fruit, the corolla and calyx usually turn pale green, the ovary shrivels, and the entire flower abscises within seven to 10 days. Therefore, fruit set was based on whether the calyx remained green with the ovary expanding after one week; ambiguous cases were eliminated from the data set so estimates of FS are conservative. Fruits have a maximum of five seeds. Seeds per fruit were counted in a subsample of fruits remaining in June 1995. Most fruit had five seeds $(x=4.6 \pm 0.62, N=25 ; 25$ fruits, four plants), so most of the variation in seed production is determined by fruit set, and those values are reported here.

Resource limitation of fruit set was estimated by comparing fruit set of pollen-augmented flowers (no pollination limitation) with the maximum fruit set observed in 1994-1995 when fruit was 100\% for most shrubs. A relative measure of percent Resource Limitation (RL) was estimated using the index shown below where $\mathrm{P}+$ equals pollen-augmented flowers and FS equals fruit set (fruits/flowers):

$$
\begin{aligned}
\% \mathrm{RL}= & 100(\text { maximum } \% \mathrm{FS} \\
& -\% \mathrm{FS} \text { of } \mathrm{P}+) / \text { maximum } \% \mathrm{FS}
\end{aligned}
$$

It should be emphasized that this index of resource limitation does not address the question of whether adding resources, such as nutrients or light, would increase flower production and/or fruit set. Rather, it addresses the question of whether the maximum fruit set possible is achieved by the set of flowers that were produced under the current circumstances (which could have been limited by resources). Also, only fruit production per flower on a shrub can be addressed because individual shrubs were too few to relegate to experimental treatments with and without pollen additions (see Zimmerman and Pyke 1988). Therefore, this measure indicates the degree of fruit abortion of a sample flower due to limited resources at the time of fruit maturation, which could likely be affected by a hurricane stripping leaves from a plant.

Pollination limitation of fruit set was tested by augmenting flowers with cross-pollen from at least two other shrubs and comparing subsequent fruit set with the fruit set of flowers exposed to natural levels of pollination. Pollination limitation (PL) was estimated using a relative index based on fruit sets (FS) of pollen- 
TABle 2. Pollination treatments on Bahama Swamp-bush, Pavonia bahamensis, over three winter-flowering seasons on San Salvador Island, Bahamas. Mean fruit set is shown for open flowers that were naturally pollinated, and for flowers augmented with cross pollen.

\begin{tabular}{|c|c|c|c|}
\hline \multirow[b]{2}{*}{ Treatment } & \multicolumn{2}{|c|}{ Numbers } & \multirow[b]{2}{*}{$\begin{array}{l}\text { Fruit set (\%) } \\
\quad \bar{x} \pm 1 \mathrm{SD}\end{array}$} \\
\hline & Plants & $\begin{array}{c}\text { Flow- } \\
\text { ers }\end{array}$ & \\
\hline \multicolumn{4}{|l|}{ 1994-1995 } \\
\hline Natural pollination & 6 & 22 & $82 \pm 30.9^{a}$ \\
\hline Abundant pollen $>60$ grains & 5 & 18 & $93 \pm 13.4^{\mathrm{a}}$ \\
\hline \multicolumn{4}{|l|}{ 1995-1996 } \\
\hline Natural pollination & 11 & 67 & $40 \pm 49.4^{\mathrm{b}}$ \\
\hline Augmented cross-pollen & 11 & 47 & $51 \pm 50.5^{b}$ \\
\hline \multicolumn{4}{|l|}{ 1996-1997 } \\
\hline Natural pollination & 7 & 64 & $11 \pm 17.9^{\mathrm{c} *}$ \\
\hline Augmented cross-pollen & 7 & 31 & $43 \pm 46.5^{\mathrm{d} *}$ \\
\hline
\end{tabular}

Notes: Fruit set equals $100 \times$ (fruits/flowers). Means within each season with different superscript letters are significantly different (Mann-Whitney $U$ test, $* P<0.05$ ).

augmented flowers $(\mathrm{P}+)$ and naturally pollinated flowers (NP) as shown below:

$\% \mathrm{PL}=100(\% \mathrm{FS}$ of $\mathrm{P}+-\% \mathrm{FS}$ of $\mathrm{NP}) /(\% \mathrm{FS}$ of $\mathrm{P}+)$

If the percentages of fruit set of naturally pollinated flowers and augmented flowers are equal, then PL = $0 \%$. If fruit set were zero for naturally pollinated flowers and $100 \%$ for pollen-augmented flowers, then \%PL would equal $100 \%$.

It is possible to calculate these relative measures for each individual plant so that means and variances could be estimated for different populations or years, and could be tested for significant differences. However, in this study, shrubs often had few flowers and nearly every available flower was used in some treatment. Therefore, these indices are based on total flowers in the population during one study season, and significant differences between years cannot be tested as variances are not available.

All animals observed visiting the flowers were recorded throughout each study period. I typically spent from two to six hours per day in the local site during most days for the entire research visit.

As an indicator of pollinator visitation, pollen grains on stigmas were counted in the field. Pollen grains are large and can easily be seen with a $10 \times$ lens. The number of pollen grains on stigmas at the end of floral life was surveyed on tagged flowers and most other available flowers in the population in all three winter seasons. The developmental stage of the flowers was noted for each flower (Rathcke, in press).

As another indicator of visitation, standing crop of nectar was measured in open flowers. Nectar was collected in $5 \mu \mathrm{L}$ microcapillary tubes to measure volume, and sugar concentrations were measured using a Bellingham refractometer (Bellingham, Kent, UK). Sugar concentrations are based on Brix values, and are cal- culated as sucrose equivalents according to Bolten et al. (1979). Nectar production by flower age was measured by bagging large flower buds with bridal veil netting and collecting nectar each day. These data are reported elsewhere (see Rathcke 1998; Rathcke, in press).

Statistics were done using SYSTAT version 5.01. Nonparametric statistics are used where data were nonnormally distributed and sample sizes were small. The small sizes often reflected the total sample size possible because shrubs are few and flower production is low, and often highly variable between shrubs per day. As a consequence, statistics are based on total flowers, rather than plants, unless noted. Typically, nearly every available flower on shrubs in the local population was tagged and was used in some treatment, so often the entire shrub and flower population on most days were being studied.

\section{RESULTS}

\section{Resource and pollination limitation of fruit set}

Fruit set of naturally pollinated flowers of $P$. $b a$ hamensis declined dramatically from $82 \%$ in 1994 1995 to $40 \%$ in $1995-1996$ to only $11 \%$ in $1996-1997$ (Table 2). This major decline in fruit set over these three winter-flowering periods reflects increases in both resource and pollination limitation.

In 1994-1995, flowers with abundant pollen $(>60$ grains/stigma) had $93 \%$ fruit set, whereas naturally pollinated flowers had $82 \%$ fruit set; however, these means were not significantly different (Table 2). Therefore, I estimated pollination limitation of fruit set to be close to zero although a few flowers may have experienced pollination limitation; overall, $2 \%$ of the flowers in the population had no pollen deposition at the end of floral life (Table 3). Because fruit set was not significantly different from $100 \%$ (the maximum), I also assume that resource limitation was minimal. Because of the small sample sizes and the imprecision of percentages, good estimates are not possible. On the other hand, most plants and flowers in the local population were studied, so data are robust and reflect population values rather than estimates. I interpret these results to indicate that both resource limitation and pollination limitation were close to zero in 1994-1995 for most shrubs (Table 3).

In 1995-1996, flowers augmented with abundant

TABLE 3. Estimates of relative pollination and resource limitation of fruit set of Bahama Swamp-bush, Pavonia bahamensis, over three winter flowering seasons on San Salvador Island, Bahamas.

\begin{tabular}{lccc}
\hline \hline & \multicolumn{3}{c}{ Limitation of fruit set (\%) } \\
\cline { 2 - 4 } & $1994-1995$ & $1995-1996$ & $1996-1997$ \\
\hline By resources & $\sim 0$ & 49 & 57 \\
By pollination & $\sim 0$ & $\sim 0$ & 74 \\
\hline
\end{tabular}

Notes: See Table 2 and Methods for equations and calculations. Near zero $\sim 0$. 
TABle 4. Flowers per plant per day for Bahama Swamp-bush, Pavonia bahamensis, in one local site on San Salvador Island, Bahamas, in different years during days in December and January.

\begin{tabular}{lccc}
\hline \hline \multicolumn{1}{c}{ Statistic } & $1994-1995$ & $1995-1996$ & $1996-1997$ \\
\hline Mean $\pm 1 \mathrm{SD}$ & $2.5 \pm 1.89$ & $3.1 \pm 3.94$ & $1.1 \pm 1.23$ \\
Plants, flowers $(N)$ & 6,15 & 9,195 & 11,207 \\
\hline
\end{tabular}

Notes: Average number of open flowers available per plant per day is shown for plants censused in all years. Differences are not significant; ANOVA, $P>0.10$ ).

pollen had $51 \%$ fruit set, so resource limitation is estimated to have reduced maximum fruit set by $49 \%$; $\mathrm{RL}=100(100 \%-51 \%) / 100 \%$ (Tables 2 and 3). Pollination limitation is estimated to be near zero because naturally pollinated flowers had $40 \%$ fruit set vs. $51 \%$ for pollen-augmented flowers, and these were not significantly different (Tables 2 and 3).

In 1996-1997, flowers augmented with abundant pollen had $43 \%$ fruit set, and resource limitation is estimated to have reduced fruit set by $57 \%$; $\mathrm{RL}=$ $(100 \%-43 \%) / 100 \%$ (Tables 2 and 3). However, naturally pollinated flowers had only $11 \%$ fruit set. Pollination limitation is estimated to have severely reduced fruit set by an additional $74 \%$; PL $=(43 \%-$ $11 \%) / 43 \%$ (Tables 2 and 3).

\section{Flower and nectar production}

Although Hurricane Lili stripped most of the leaves from $P$. bahamensis in October 1996, the mean number of flowers open per day per plant did not change significantly over the three years (Table 4; see also Rathcke, in press). In addition, nectar production per flower did not decrease in 1996-1997 relative to prehurricane levels in 1994-1995. In 1994-1995, total nectar production per flower over its lifetime was estimated to be $225 \mu \mathrm{L}$, whereas in 1996-1997, it was $458 \mu \mathrm{L}$ (Rathcke, in press). These differences may partly reflect different sampling methods and sample sizes, but these data indicate that nectar certainly did not decrease, and may even have increased, after the hurricane.

TABle 5. Pollen deposition on stigmas of Bahama Swampbush, Pavonia bahamensis, over three winter flowering seasons on San Salvador Island, Bahamas.

\begin{tabular}{lclc}
\hline \hline \multirow{2}{*}{$\begin{array}{l}\text { Pollen grains/ } \\
\text { stigma }\end{array}$} & \multicolumn{3}{c}{ Percentage of flowers } \\
\cline { 2 - 4 } & $1994-1995$ & $1995-1996$ & $1996-1997$ \\
\hline None & 2 & 13 & 51 \\
$>20$ & 85 & 65 & 37 \\
$>50$ & 46 & 45 & 7 \\
Mean \pm 1 SD & $58 \pm 45.5$ & $48 \pm 34.5$ & $14 \pm 22.4$ \\
Flowers $(N)$ & 22 & 68 & 65 \\
Plants $(N)$ & 6 & 11 & 7 \\
\hline
\end{tabular}

Notes: Pollen grains were counted at the end of floral life. Mean and standard deviations are shown for number of pollen grains.

\section{Pollination}

Based on field observations, flower visitation by bird pollinators decreased greatly between 1994-1995 and 1996-1997. In 1994-1995, Bananaquits were the most common visitors to $P$. bahamensis flowers. They were in small flocks of five to seven birds, and appeared to remain in the local area, visiting flowers continuously throughout the day (B. Rathcke, personal observations). I observed flower visits by birds every day during 10 research days in 1994-1995. Bahama Woodstars, usually males, visited several times a day, typically probing one to 10 flowers before leaving the local site. In 1995-1996, Bananaquits were infrequently seen or heard in the site, but Bahama Woodstars appeared to visit about as frequently as in 1994-1995. In 19961997, both Bananaquits and Bahama Woodstars appeared to be absent in the site. I never saw or heard a Bananaquit in the research site during 13 research days (see also Rathcke 1998). I saw or heard individual Bahama Woodstars only three times during 13 research days and saw no visits to flowers during this winter study period.

The decline in bird visitation to flowers over the three years is supported by the decreased pollen deposition on stigmas of flowers by the last day of receptivity (Table 5). In 1994-1995 only $2 \%$ of the flowers had no pollen deposition at the end of floral life, whereas in $1996-1997,51 \%$ of the flowers had no pollen deposition. Although flowers have only five ovules (and five possible seeds), flowers with five to 20 pollen grains had only $19 \%$ fruit set indicating that 20 or more pollen grains are necessary for maximum fruit set (Rathcke, in press). Therefore, in 1996-1997, only 37\% of the flowers had effective pollen loads vs. $85 \%$ in 1994-1995 and 65\% in 1995-1996.

The decline in bird visitation to flowers between 1994-1996 and 1996-1997 is also supported by the occurrence of greatly increased standing crops of nectar (nectar remaining in open, visited flowers) in 19961997 (Table 6). In fact, in winter 1996-1997, nectar was overflowing from flowers. For this period, standing crop measurements are probably underestimates because nectar had often dripped out of flowers. No flowers were empty during measurements of standing crops in 1996-1997 ( $N=52$ flowers, eight plants, three days). Standing crops of nectar were significantly higher in 1994-1995 than in 1995-1996 (Table 6), but this 
TABle 6. Standing crop of nectar in Bahama Swamp-bush (Pavonia bahamensis), flowers during three different years.

\begin{tabular}{lccc}
\hline \hline \multirow{2}{*}{\multicolumn{1}{c}{ Statistic }} & \multicolumn{3}{c}{ Nectar/flower/day $(\mu \mathrm{L})$} \\
\cline { 2 - 4 } & $1994-1995$ & $1995-1996$ & $1996-1997$ \\
\hline Mean \pm 1 SD & $21 \pm 39.1^{\text {a }}$ & $5 \pm 11.3^{\mathrm{b}}$ & $62 \pm 75.8^{\mathrm{c}}$ \\
Plants, flowers $(N)$ & 6,18 & 9,49 & 8,52 \\
\hline
\end{tabular}

Notes: Mean and standard deviation of nectar per flower $(\mu \mathrm{L} / \mathrm{d})$ are shown, along with sample sizes. Values with different superscripts are significantly different (Student's $t$ tests corrected for sample sizes; $P<0.01$ ).

may reflect larger sample sizes in 1995-1996 and should not be overinterpreted.

\section{DISCUSSION}

This study provides the first empirical evidence that hurricanes can significantly limit both resources and pollination for fruit set of a bird-pollinated plant. Resource limitation of fruit set increased for $P$. bahamensis, reducing fruit set by 49\% in 1995-1996 and $57 \%$ in 1996-1997 (Table 3). In 1996-1997 is seems likely that resources were less available for fruit set because Hurricane Lili stripped the leaves off most shrubs and trees in October 1996. Local observers noted that the leaves were stripped from most plants on the island unless plants were protected. A concurrent leaf demography study on $P$. bahamensis showed that virtually no old, marked leaves remained in a January 1997 census (Rathcke, unpublished data) in contrast to previous years when older, mature leaves were present during our winter study periods. In the 1996-1997 study, most leaves were bright green and tender indicating they were recently formed. Herbivory remained generally low throughout the three years and probably cannot account for differences in fruit set before and after the hurricanes (Rathcke, unpublished data). The high resource limitation in 1995-1996 is harder to explain. Perhaps here is a trade-off after an especially high fruit set year in 1994-1995 or perhaps plants did suffer some major effects of the mild Hurricane Erin in 1995. Leaf stripping was not evident although clearly the hurricane had removed local debris in the lakes and probably had strong effects on the salinity the shrubs experienced. Certainly salt water was blown onto the plants from the lake as most of the debris among the mangroves was completely removed.

Resource limitation of fruit set after hurricanes may seem to be a likely response of plants, but no significant effects on fruit set have been found for an orchid (Ackerman and Moya 1996) or a fig (Bronstein and HossertMcKey 1995). Although fruit set of P. bahamensis apparently became resource limited after the hurricanes, neither subsequent flower production nor nectar production was decreased. Other studies have also found no effects on flower production (Bronstein and HossertMcKey 1995; Ackerman and Moya 1996). These results support the assumption that the common declines in nectarivorous birds after hurricanes reflect immediate flower destruction and not subsequent flowering after two to three months (Askins and Ewert 1991, Lynch 1991, Will 1991, Wauer and Wunderle 1992, Wunderle 1995, Murphy et al. 1998). Given that hurricanes can open up the canopy, the increased sun radiation may compensate for any leaf loss.

The severe pollination limitation of fruit set in 19961997 can be strongly attributed to the decline in the two pollinating bird species, Bananaquits and Bahama Woodstars, after Hurricane Lili. In 1994-1995 before the hurricanes, both species were frequent flowers visitors and were observed every day in the study site. In 1996-1997, birds were almost never seen in the study site or in nearby areas. The lack of flower visitation in 1996-1997 compared to the other two years is supported by both lower pollen depositions on stigmas and by lower removal rates of nectar. A mist net census of birds adjacent to my study site confirms that Bananaquit populations were at unusually low numbers in January 1997, after the October 1996 Hurricane Lili (Murphy et al. 1998).

The absence of Bananaquits in the study site in 1996-1997 appears to reflect a general population decline throughout the island. Very few Bananaquits were seen in a general island survey throughout January 1997 (Murphy et al. 1998). The population crash of Bananaquits was most likely caused by destruction of flower resources after Hurricane Lili rather than by any direct effects of the winds increasing mortality (Murphy et al. 1998). Insectivorous birds did not decline in abundance which further suggests that bird mortality was caused by destruction of plant resources and not by the direct effects of the hurricane (Murphy et al. 1998). The only other bird species that decreased was the White-eyed Vireo which tends to be frugivorous (Murphy et al. 1998). Bahama Woodstars and Bahama Mockingbirds were not captured successfully by mist nets, so reliable data are not available on their population numbers (Murphy et al. 1998).

If nectarivorous bird populations had not decreased after the hurricane, flower visitation and pollination could also have been reduced if birds changed their foraging sites with changes in floral resources (e.g., Elmqvist et al. 1992, Grant et al. 1997). However, this seems an unlikely explanation for these results of this study. Neither subsequent flower production nor nectar production showed any decrease in $P$. bahamensis three months after the hurricanes (Tables 4 and 6). The amount of nectar available in the site probably remained relatively constant over the three years (19941997) which suggests that resources would have attracted and supported similar numbers of birds in all three years. In fact, Murphy et al. (1998) suggest that in 1996-1997, a few dominant Bananaquits in the area defended the high nectar resources of $P$. bahamensis, and therefore, were in better condition than other birds in other habitats. However, the reasons for the low 
visitation of Bananaquits in 1995-1996 is not clear. Whether foraging behavior changed or populations declined after the mild hurricane Erin is unknown.

No compensatory pollination of $P$. bahamensis occurred when the populations of these two bird pollinators declined. In 1996-1997, flowers were dripping nectar and would have been more available to shorttongued birds (Wolf and Stiles 1989). A single foraging bout by a Bahama Mockingbird was observed, but this additional visitor species did not provide a "fail-safe" pollination mechanism as has been seen for some other tropical plant species (Wolf and Stiles 1989). However, San Salvador has only two nectarivorous bird species so the pollination of $P$. bahamensis is constrained by bird species availability. Because island species often have fewer pollinators than mainland species (Lack 1976, Woodell 1979, Feinsinger et al. 1982, 1985, Spears 1987, Elmqvist et al. 1992), they may be especially vulnerable to disturbances, such as hurricanes, that disrupt their pollinators. Having more pollinator species can provide resiliency (Rathcke 1988, Rathcke and Jules 1993, Rathcke 1998).

The effect of hurricane destruction on pollinators will depend upon the degree of damage to plants and pollinators (area, intensity, and frequency; Connell 1978), and the speed of recovery by plants (Vandermeer et al. 1996) and pollinator populations. Will (1991) noted that birds still had not rebounded after five years in a hurricane-devastated forest of Nicaragua, but the forest destruction there occurred on a very large scale of 1000s of hectares. On San Salvador Island, Bananaquits have recovered quickly and apparently were near prehurricane levels in February 1998, $1.5 \mathrm{yr}$ after Hurricane Lili (M. Murphy, personal communication). Therefore, the hurricane effect on these bird pollinators was relatively short lived. Other pollinators, such as insects, may rebound quickly or even increase after hurricanes. A hawkmoth pollinator of an orchid appeared to become a more common visitor (although pollen deposition was lower) after a hurricane (Ackerman and Moya 1996). Fig wasps appeared to return to prehurricane levels within months after Hurricane Hugo (Category 4) in Florida (Bronstein and HossertMcKey 1995). Whether insect-pollinated plants typically have a lower risk of pollination limitation than bird-pollinated plants after hurricanes remains to be documented.

Even if fruit set reduction by hurricanes occurs for only a brief time due to either resource limitation and/ or pollination limitation, it could have long-term effects on recruitment because timing of seed dispersal can be crucial. Hurricanes can provide major opportunities for new recruitment of plant individuals by opening up gaps in the canopy (Connell 1978, Boucher 1990, Vandermeer et al. 1996). Therefore, even brief reductions of fruit set after hurricanes could have significant effects on population growth and long-term persistence. As for many long-lived plants, seedlings of $P$. bahamensis are rarely seen. It seems unlikely that there is a persistent seed bank, but this is not known. Whether the short-term reduction in fruit set had any effect on subsequent recruitment is unknown.

Although fruit set of $P$. bahamensis was resource limited after both mild and severe hurricanes, fruit set was more strongly pollination limited $(74 \%)$ than resource limited (57\%) in 1996-1997 after the severe Hurricane Lili. Although resource limitation of fruit set may affect many plant species, bird-pollinated species may be even more severely disadvantaged because they may experience a double jeopardy of both resource limitation and pollination limitation of fruit set. Whether this differentially affects the recruitment of birdpollinated plant species compared to other plant species after hurricanes remains to be determined. It will be interesting to determine if bird-pollinated species that commonly experience hurricanes have other mechanisms to compensate for this pollination disadvantage.

\section{ACKNOWLEDGMENTS}

I thank the Bahamian Field Station and the staff for all their support and logistical help. I thank Lee Kass and Bob Hunt for their continued research and personal support. Lee Kass also collected data for me at crucial times. Michael Murphy and David Ewert provided data or information on birds and hurricanes.

\section{Literature Cited}

Ackerman, J. D., and S. Moya. 1996. Hurricane aftermath: resiliency of an orchid-pollinator interaction in Puerto Rico. Caribbean Journal of Science 32;369-374.

Askins, R. A., and D. N. Ewert. 1991. Impact of Hurricane Hugo on bird populations on St. John, U.S. Virgin Islands. Biotropica 23;481-487.

Bahamas Department of Meteorology. No date. Hurricane Erin in the Bahamas, 30 July-2 August 1995. Bahamas Department of Meteorology, Nassau, Bahamas.

Bahamas Department of Meteorology. No date. Hurricane Lili in the Bahamas 18-19 October 1996. Bahamas Department of Meteorology, Nassau, Bahamas.

Bolten, A. B., P. Feinsinger, H. G. Baker, and I. Baker. 1979. On the calculation of sugar concentration in flower nectar. Oecologia 41;301-304.

Boose, E. R., D. R. Foster, and M. Fluet. 1994. Hurricane impacts to tropical and temperate forest landscapes. Ecological Monographs 64;369-400.

Boucher, D. H. 1990. Growing back after hurricanes. Bioscience 40;163-166.

Bronstein, J. L., and M. Hossert-McKey. 1995. Hurricane Andrew and a Florida fig pollination mutualism: resilience of an obligate interaction. Biotropica 27;373-381.

Connell, J. H. 1978. Diversity in tropical forests and coral reefs. Science 199;1302-1310.

Correll, D. S., and H. B. Correll. 1982. Flora of the Bahama Archipelago. J. Cramer: In der A. R. Gantner Verlag Kommanditgeselleschaft.

Elmqvist, T., P. A. Cox, W. E. Rainey, and E. D. Pierson. 1992. Restricted pollination on oceanic islands: pollination of Ceiba pentandra by flying foxes in Samoa. Biotropica 24;15-23.

Eshbaugh, W. H., and T. K. Wilson. 1996. On the need to conserve Bahamian floral diversity. Pages 77-82 in N. B. Elliott, D. C. Edwards, and P. J. Godfrey, editors. Proceedings of the Sixth Symposium of the Natural History of the Bahamas. Bahamian Field Station, San Salvador, Bahamas. 
Feinsinger, P., L. A. Swarm, and J. A. Wolfe. 1985. Nectarfeeding birds on Trinidad and Tobago: comparison of diverse and depauperate guilds. Ecological Monographs 55; $1-28$.

Feinsinger, P., J. A. Wolfe, and L. A. Swarm. 1982. Island ecology: reduced hummingbird diversity and the pollination biology of plants, Trinidad and Tobago, West Indies. Ecology 63;494-506.

Fryxell, P. A. 1999. Pavonia Cav. (Malvaceae). Flora Neotropica $76 ; 1-288$.

Gentry, A. H. 1974. Coevolutionary patterns in Central American Bignoniaceae. Annals of the Missouri Botanical Garden 81;728-759.

Grant, G. S., P. Craig, and P. Trail. 1997. Cyclone-induced shift in foraging behavior in flying foxes in American Samoa. Biotropica 29;224-228.

Howe, H. C., and C. C. Westley. 1988. Ecological Relationships of Plants and Animals. Oxford University Press, New York, New York, USA.

Lack, D. 1976. Island Biology. Blackwell Science Publications, Oxford, UK.

Lynch, J. F. 1991. Effects of Hurricane Gilbert on birds in a dry tropical forest in the Yucatan Peninsula. Biotropica 23; 488-496.

Murphy, M. T., K. L. Cornell, and K. L. Murphy. 1998. Winter bird communities on San Salvador, Bahamas. Journal of Field Ornithology 69;402-414.

Pascarella, J. B. 1998. Resiliency and response to hurricane disturbance in a tropical shrub, Ardisia escallonioides (Myrsinaceae), in south Florida. American Journal of Botany $\mathbf{8 5} ; 1207-1215$.

Rathcke, B. 1988. Interactions for pollination among coflowering shrubs. Ecology 69;446-457.

Rathcke, B. 1998. Bird pollination of the endemic Bahama Swamp-bush, Pavonia bahamensis Hitchc. (Malvaceae): the risk of specialization. Pages 105-110 in T. K. Wilson, editor. Proceedings of the Seventh Symposium on the Natural History of the Bahamas. Bahamian Field Station, San Salvador, Bahamas.

Rathcke, B. J. In press. Birds, pollination reliability, and green flowers in an endemic island shrub, Pavonia bahamensis (Malvaceae). Rhodora.

Rathcke, B. J., and E. S. Jules. 1993. Habitat fragmentation and plant-pollinator interactions. Current Science 65;273277.

Rathcke, B., L. B. Kass, and R. E. Hunt. 1996. Preliminary observations on plant reproductive biology in mangrove communities on San Salvador Island, Bahamas. Pages 8796 in N. B. Elliott, D. C. Edwards, and P. J. Godfrey, editors. Proceedings of the Sixth Symposium on the Natural History of the Bahamas. Bahamian Field Station, San Salvador, Bahamas.

Reilly, A. E. 1991. The effects of Hurricane Hugo in three tropical forests in the U.S. Virgin Islands. Biotropica 23; 414-419.
Roth, L. C. 1992. Hurricanes and mangrove regeneration: effects of Hurricane Joan, October 1988, on the vegetation of Isla del Venado, Bluefields, Nicaragua. Biotropica 24; 375-384.

Shaklee, R. V. 1996. Weather and Climate: San Salvador Island, Bahamas. Bahamian Field Station, San Salvador, Bahamas.

Smith, R. R. 1993. Field guide to the vegetation of San Salvador Island, The Bahamas. Second Edition. Bahamian Field Station, San Salvador, Bahamas.

Spears, E. E., Jr. 1987. Island and mainland pollination ecology of Centrosema virginianum and Opuntia stricta. Journal of Ecology 75;351-362.

Vandermeer, J., D. Boucher, I. Perfecto, and I. Granzow de la Cerda. 1996. A theory of disturbance and species diversity: evidence from Nicaragua after Hurricane Joan. Biotropica 28;600-613.

Vandermeer, J., N. Zamora, K. Yih, and D. Boucher. 1990. Regeneración inicial en una selva tropical en la costa caribeňa de Nicaragua después del huracán Juana. Revista Biologica Tropica 38;347-359.

Waide, R. B. 1991. The effect of Hurricane Hugo on bird populations in the Luquillo Experimental Forest, Puerto Rico. Biotropica 23;475-480.

Walker, L. R., J. Voltzow, J. D. Ackerman, D. S. Fernandez, and N. Fetcher. 1992. Immediate impact of Hurricane Hugo on a Puerto Rican rain forest. Ecology 73;691-694.

Wauer, R. H. and J. M. Wunderle, Jr. 1992. The effect of Hurricane Hugo on bird populations on St. Croix, U.S Virgin Islands. Wilson Bulletin 104;656-669.

White, B. 1991. Common Birds of San Salvador Island, Bahamas. Bahamian Field Station, San Salvador, Bahamas.

Will, T. 1991. Birds of a severely hurricane-damaged Atlantic coast rain forest in Nicaragua. Biotropica 23;4997-507.

Wolf, L. L. and G. F. Stiles. 1989. Adaptations for 'fail-safe' pollination of specialized ornithophilous flowers. American Midland Naturalist 121;1-10.

Woodell, S. R. J. 1979. The role of unspecialized pollinators in the reproductive success of Aldabran plants. Philosophical Transactions of the Royal Society London Series B 286; $99-108$.

Wunderle, J. M., Jr. 1995. Responses of bird populations in a Puerto Rican forest to Hurricane Hugo: the first 18 months. Condor 97;879-896.

Wunderle, J. M. Jr., D. J. Lodge, and R. B. Waide. 1992. Short-term effects of Hurricane Gilbert on terrestrial bird populations on Jamaica. Auk 109;148-166.

Zimmerman, J. K., E. M. Everham III, R. B. Waide, D. J. Lodge, C. M. Taylor, and N. V. L. Brokaw. 1994. Responses of tree species to hurricane winds in subtropical wet forest in Puerto Rico: implications for tropical tree life histories. Journal of Ecology 82;911-922.

Zimmerman, M., and G. H. Pyke. 1988. Reproduction in Polemonium: assessing the factors limiting seed set. American Naturalist 131:723-738. 